\title{
Perancaangan Sistem Informasi Manajemen Permintaan Barang Berbasis Web pada PT MNC SKY VISION Tbk
}

\author{
Bobi Agustian', Irpan Kusyadi², Yusep Jaelani ${ }^{3}$ \\ 1,2,3 Teknik Informatika, Universitas Pamulang, Tangerang Selatan, Banten, Indonesia \\ e-mail: ${ }^{1}$ dosen00679@unpam.ac.id, ${ }^{2}$ dosen00673@unpam.ac.id, ${ }^{3}$ yusepjailani@gmail.com \\ Submitted Date: July 22 $2^{\text {nd }}, 2019$ \\ Reviewed Date: August $12^{\text {th }}, 2019$ \\ Revised Date: October 2 ${ }^{\text {nd }}, 2019$ \\ Accepted Date: October $4^{\text {th }}, 2019$
}

\begin{abstract}
At present, the world has entered the era of information-based competition. Information becomes a valuable asset for a business institution in winning business competition. At PT MNC Sky Vision Tbk is currently using an information system in the form of the use of computer equipment in carrying out its work activities, but in processing data on demand for goods currently in processing data is still less efficient, fast, accurate, and there are still errors in the monthly report, because when In the average daily demand for goods there are 10 requests, both departments / divisions and from branch offices namely KPP, KPD and KPU, which number around 46 departments / divisions and 75 branch offices, for the number of goods requested by the Demand Management Information System Web-Based Goods at PT. MNC Sky Vision Tbk. In one transaction, there were 8 types out of a total of 738 types of goods, so in the process of recapitulating data, demand for goods requires a long time either in adding data, changing data, deleting data and searching data for items needed in a month. Based on these problems, it is needed an application in processing demand data, especially office stationery (ATK) and other supporting operational activities of the office. In this study, the data collection method uses observation, interviews and literature studies. The application is compiled with the procedure of development stage which includes analysis of needs, making data flow diagrams, implementation using PHP as a programming language and MySql as the database. From the research conducted, a Web-based demand management information system software is produced, which can help in day-to-day office operations, namely data storage or data recap and also avoid losses due to human error.
\end{abstract}

Keywords: Website, Management Information System, Stationery

\begin{abstract}
Abstrak
Saat ini, dunia telah memasuki era persaingan berbasiskan informasi. Informasi menjadi aset yang berharga bagi suatu institusi bisnis dalam memenangkan persaingan bisnis. Pada PT MNC Sky Vision Tbk saat ini sudah menggunakan sistem informasi berupa pemakaian perangkat komputer dalam melaksanakan aktifitas kerjanya, namun dalam mengolah data permintaan barang saat ini dalam pengolahan datanya masih kurang efisien, cepat, akurat, dan masih adanya kesalahan dalam laporan perbulannya, karena saat ini dalam kegiatan permintaan barang rata-rata sehari ada 10 permintaan, baik itu departemen/divisi maupun dari kantor cabang yaitu KPP, KPD dan KPU, yang jumlahnya sekitar 46 departemen/divisi dan 75 kantor cabang, untuk jumlah barang yang diminta Sistem Informasi Manajemen Permintaan Barang Berbasis Web Pada PT. MNC Sky Vision Tbk.dalam sekali transaksi sekitar 8 jenis dari total 738 jenis barang, sehingga dalam pengerjaannya untuk mengrekapitulasi data permintaan barang membutuhkan waktu yang lama baik itu dalam penambahan data, perubahan data, penghapusan data serta dalam pencarian data barang yang diperlukan dalam perbulan. Berdasarkan permasalahan tersebut, maka dibutuhkan aplikasi dalam pengolahan data permintaan barang khususnya alat tulis kantor (ATK) dan barang penunjang kegiatan operasional kantor lainnya. Dalam penelitian ini, metode pengumpulan data menggunakan observasi, wawancara dan studi literatur. Aplikasi disusun dengan prosedur tahap pengembangan yang mencakup analisis kebutuhan, pembuatan diagram alir data, implementasi dengan menggunakan PHP sebagai bahasa pemrograman dan MySql sebagai databasenya. Dari penelitian yang dilakukan dihasilkan sebuah perangkat lunak Sistem informasi manajemen permintaan barang berbasis Web, yang dapat membantu dalam
\end{abstract}


operasional kantor sehari-hari, yaitu penyimpanan data atau rekap data dan juga menghindari kerugian akibat kesalahan manusia.

\section{Kata kunci: Website, Sistem Informasi Manajemen, Alat Tulis}

\section{Pendahuluan}

Perkembangan teknologi dan informasi yang semakin berkembang, mendorong perkembangan manusia dalam melakukan aktivitasnya, satu manfaat dari perkembangan teknologi ini dapat mempermudah memperoleh informasi yang cepat dan akurat. Untuk mendapatkan dan menghasilkan informasi, teknologi komputer adalah alat bantu yang paling tepat. Penggunaan komputer bisa diterapkan dalam bidang dan semua kalangan. Kemajuan teknologi inilah yang mengharuskan instansi baik negeri maupun swasta mengikuti perkembangan teknologi dan terus meningkatkan kemampuannya didalam mengelola data dan informasi yang lebih akurat dan efisien.

Website adalah salah satu layanan yang didapat oleh pemakai komputer yang terhubung ke internet. Website ini menyediakan informasi bagi pemakai komputer yang terhubung ke internet. Website atau situs dapat diartikan sebagai suatu kumpulan halaman-halaman yang dipergunakan untuk menampilkan berbagai informasi teks, gambar diam atau bergerak, animasi, suara, dan atau gabungan dari semuanya baik yang bersifat statis maupun dinamis yang membentuk satu rangkaian bangunan yang saling terkait dimana masingmasing dihubungkan dengan jaringan-jaringan halaman (hyperlink).

Website adalah koleksi sumber informasi kaya grafis yang saling berhubungan satu sama lain dalam internet yang lebih besar. Website merupakan halaman situs sistem informasi yang dapat diakses secara cepat. Website ini didasari dari adanya perkembangan teknologi informasi dan komunikasi. Melalui perkembangan teknologi informasi, tercipta suatu jaringan antar komputer yang saling berkaitan. jaringan yang dikenal dengan istilah internet secara terus-menerus menjadi pesan-pesan elektronik, termasuk e-mail, transmisi file, dan komunikasi dua arah antar individu atau komputer (JavaCreatifity, 2014).

Web Server adalah suatu server internet yang menggunakan protokol HTTP (Hypertext Transfer Protocol) untuk melayani semua proses pentransferan data. Komputer yang berada pada jaringan akan memiliki alamat yang unik, demikian juga dengan sebuah situs web pada internet. Situs tersebut memiliki alamat yang unik juga. Aktivitas utama yang berlangsung di internet adalah pengiriman/penerimaan e-mail dan pencarian informasi yang telah disediakan oleh Web Server atau sering kita sebut browsing atau surfing (Syahputra, 2003).

PHP adalah singkatan dari Personal Home Page yang merupakan bahasa standar yang digunakan dalam dunia website. PHP merupakan bahasa pemrograman yang berbentuk script yang diletakkan didalam web server. PHP dapat diartikan sebagai Hypertext Preeprocessor. Ini merupakan bahasa yang hanya dapat berjalan pada server yang hasilnya dapat ditampilkan pada klien. Interpreter PHP dalam mengeksekusi kode PHP pada sisi server disebut server side, berbeda dengan mesin maya Java yang mengeksekusi program pada sisi klien (Peranginangin, 2006).

MYSQL merupakan RDBMS (server database) yang mengelola database dengan cepat menampung dalam jumlah sangat besar dan dapat di akses oleh banyak user. Sedangkan Menurut Kadir (2008) MySQL adalah sebuah software open source yang digunakan untuk membuat sebuah database. Berdasarkan pendapat yang dikemukakan di atas dapat ditarik kesimpulan bahwa MySQL adalah Suatu software atau program yang digunakan untuk membuat sebuah basis data yang bersifat open source (Raharjo, 2011).

(UML) merupakan bahasa spesifikasi standar yang digunakan untuk mendokumentasikan, menspesifikasikan dan membanngun sebuah perangkat lunak. UML merupakan metodologi dalam mengembangkan sistem berorientasi objek dan juga merupakan alat untuk mendukung pengembangan sistem (Gata \& Gata, 2013).

PT MNC Sky Vision Tbk saat ini sudah menggunakan sistem informasi berupa pemakaian perangkat komputer dalam melaksanakan aktivitas kerjanya, namun dalam mengelola data permintaan barang khususnya Alat tulis kantor (ATK), dan barang penunjang operasional kantor lainnya, saat ini dalam mengelola datanya masih kurang efisien, cepat dan akurat, yaitu karyawan apabila ingin melakukan barang harus mencatat terlebih dahulu barang yang diinginkan dan berapa jumlah barang tersebut,setelah dicetak selanjutunya minta tandatangan dari leader atau kepala bagian,setelah itu kertas yang sudah di isi dan di tandatangani langsung di bawa ke bagian ATK sampai di gudang ATK, kertas yang tadi dibuat diserahkan selanjutnya menuggu verifikasi data permintaan 
barang oleh kepala bagian ATK, setelah mendapatkan ijin dari pimpinan terkait barulah stok gudang ATK menyiapkan barang-barang yang diminta,membuat surat jalan dan menyiapkan transaksi brang tersebut,setelah semuanya selesai barang yang diminta sudah bisa dibawa. dan masih adanya kesalahan dalam laporan perbulannya, karena saat ini dalam kegiatan permintaan barang rata-rata sehari ada 10 permintaan, baik itu departemen/divisi maupun dari kantor cabang yaitu KPP, KPD dan KPU, yang jumlahnya sekitar 46 departemen/divisi dan 75 kantor cabang, untuk jumlah barang yang diminta dalam sekali transaksi sekitar 8 jenis dari total 738 jenis barang,yang dimana apabila dikumpulkan dalam sekali transaksi permintaan barang yaitu 1 lembar kertas untuk 1 lembar permintaan,jadi kurang lebih ada 10 kertas yang di gunakan setiap harinya, sehingga dalam pengerjaannya untuk mengrekapitulasi laporan data permintaan barang membutuhkan waktu yang lama baik itu dalam penambahan data, perubahan data, penghapusan data, mengetahui stok barang, dan juga history permintaan barang dalam perbulan.

Pada PT MNC Sky Vision Tbk proses permintaan barang alat tulis kantor (ATK) dan barang penunjang operasional kantor yang lain belum menggunakan sistem baru yang lebih cepat dan tepat seiring dengan perkembangan teknologi yang semakin pesat, yaitu dengan menggunakan sistem yang memamfaatkan aplikasi website. Teknologi internet yang berkembang semakin pesat akan mengalami perkembangan juga tehadap aplikasi website, karena website memiliki kelebihan seperti, kita dapat menjalankan aplikasi berbasis website dimanapun kapanpun tanpa harus melakukan penginstalan, dapat dijalankan di sistem operasi manapun

Setelah sistem selesai diimplementasi maka peneliti akan melakukan pengujian. Pengujian adalah satu set aktifitas yang direncanakan dan sistematis untuk menguji atau mengevaluasi kebenaran yang diinginkan. Aktifitas pengujian terdiri dari satu set atau sekumpulan langkah dimana dapat menempatkan desain kasus uji yang spesifik

Kualitas perangkat lunak bergantung kepada kepuasan pelanggan dan kualitas sebuah perangkat lunak perlu dijaga dengan sejumlah alasan sebagai berikut (Rosa \& Shalahuddin, 2014):

1. Dapat bertahan hidup didunia bisnispera ngkat lunak.

2. Dapat bersaing dengan perangkat lunak lainnya

3. Penting untuk pemasaran global
4. Mengefektifkan biaya agar tidak banyak membuang perangkat lunak karena kegagalan pemasaran atau produksi

5. Mempertahankan pelanggan dan meningkatkan keuntungan.

Pada peneletian ini penulis melakukan pengujian sistem menggunakan metode black box testing. Pengujian black box merupakan pengujian perangkat lunak dari segi spesifikasi fungsional tanpa menguji desain dan kode program untuk mengetahui apakah fungsi, masukan dan keluaran dari perangkat lunak sesuai dengan spesifikasi yang dibutuhkan. Metode Blackbox Testing merupakan salah satu metode yang mudah digunakan karena hanya memerlukan batas bawah dan batas atas dari data yang di harapkan,Estimasi banyaknya data uji dapat dihitung melalui banyaknya field data entri yang akan diuji, aturan entri yang harus dipenuhi serta kasus batas atas dan batas bawah yang memenuhi. Dan dengan metode ini dapat diketahui jika fungsionalitas masih dapat menerima masukan data yang tidak diharapkan maka menyebabkan data yang disimpan kurang valid (Mustaqbal, Firdaus, \& Rahmadi, 2015).

\section{Metode Waterfall}

Model SDLC air terjun (waterfall) sering juga disebut model sekuensial linier (sequential linier) atau alur hidup klasik (classic life cycle). Model air terjun menyediakan pendekatan alur hidup perangkat lunak secara sekuential atau terurut dimulai dari analisis, desain, pengkodean, pengujian, dan tahap pendukung (support).

a. Analisis Kebutuhan Perangkat Lunak Proses pengumpulan kebutuhan dilakukan secara intensif untuk menspesifikasikan kebutuhan perangkat lunak agar dapat dipahami perangkat lunak seperti apa yang dibutuhkan oleh user. Spesifikasi kebutuhan perangkat lunak pada tahap ini perlu untuk didokumentasikan.

b. Desain Desain perangkat lunak adalah proses multi langkah yang fokus pada desain pembuatan program perangkat lunak termasuk struktur data, arsitektur perangkat lunak, representasi antarmuka, dan prosedur pengkodean. Tahap ini mentrannslasi kebutuhan perangkat lunak dari tahap analisis kebutuhan ke representasi desain agar dapat diimplementasikan menjadi program pada tahap selanjutnya. Desain perangkat lunak yang dihasilkan pada tahap ini juga perlu didokumentasikan.

c. Pembuatan Kode Program Desain harus ditranslasikan kedalam program perangkat 
lunak. Hasil dari tahap ini adalah program komputer sesuai dengan desain yang telah dibuat pada tahap desain.

d. Pengujian Pengujian fokus pada perangkat lunak secara dari segi lojik dan fungsional dan memastikan bahwa semua bagian sudah diuji. Hal ini dilakukan untuk meminimalisir kesalahan (error) dan memastika keluaran yang dihasilkan sesuai dengan yang diinginkan.

e. Pendukung atau Pemeliharaan (maintenance) Tidak menutup kemungkinan sebuah perangkat lunak mengalami perubahan ketika sudah dikirimkan ke user. Perubahan bisa terjadi karena adanya kesalahan yang muncul dan tidak terdeteksi saat pengujian atau perangkat lunak harus beradaptasi dengan lingkungan baru. Tahap pendukung atau pemeliharaan dapat mengulangi proses pengembangan mulai dari analisis spesifikasi untuk perubahan perangkat lunak yang sudah ada, tapi tidak untuk membuat perangkat lunak baru (Rosa \& Shalahuddin, 2014).

\section{Hasil dan Pembahasan}

a. Requiment definition

Pada tahap ini merupakan tahapan mencari informasi mengenai sistem yang diteliti dengan melakukan metode pengumpulan data sehingga ditemukan kelebihan dan kekurangan. Tahap ini dilakukan untuk mencari pemecah masalah dan menganalisa bagaimana sistem akan dibangun untuk memecahkan masalah pada sistem sebelumnya. Adapun beberapa aspek yang dibutuhkan adalah sebagai berikut:

1. Dokumentasi permintaan barang.

2. Fungsi untuk cetak surat jalan dan surat pengeluaran barang.

3. Dokumentasi data permintaan, barang, data cabang

b. System And Software Design

Desain perangkat lunak merupakan suatu proses multi langkah yang berfokus pada suatu desain pembuatan program perangkat lunak termasuk struktur data, arsitektur perangkat lunak, rancangan antar muka dan prosedur pengkodean. Tahap ini mentranslasi kebutuhan perangkat dari tahap analisis kebutuhan ke reprentasi desain supaya bisa di implementasikan program pada tahap selanjutnya. Desain perangkat lunak yang di hasilkan pada tahap ini juga perlu di dokumentasikan.

1. ERD (Entity Relationship Diagram)

Merupakan gambaran dari entitas yang saling berkaitan di dalam sistem yang akan dibuat. Adapun entitasnya adalah sebagai berikut:
a. Supplier
b. Petugas ATK
c. Admin
d. Database barang
e. Pimpinan
f. Kepala bagian

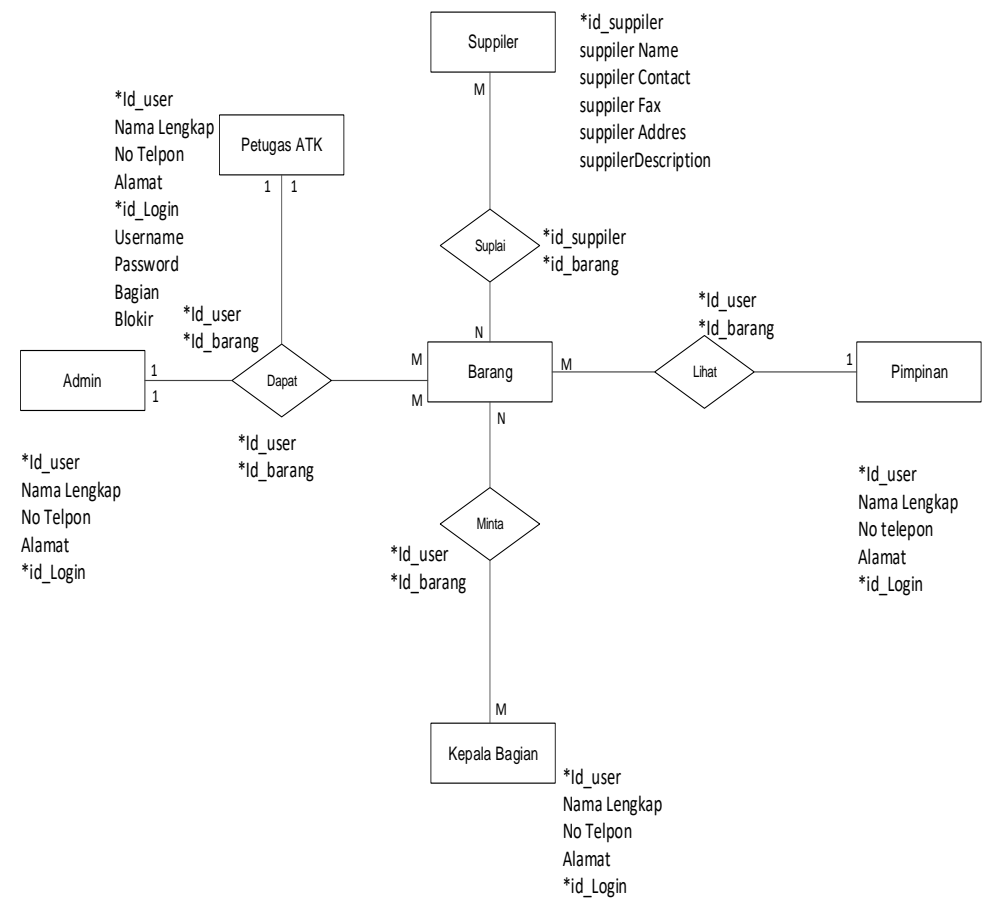

Gambar 1 Entity Relationship Diagram 
2. Use Case Diagram

Use Case adalah merupakan sebuah teknik yang biasanya digunakan pada pengembangan sebuah perangkat lunak yang digunakan untuk menangkap kebutuhan fungsional dari suatu sistem yang akan dibuat. Use Case digunakan untuk menjelaskan interaksi yang terjadi antara aktor dengan sistem yang akan dibuat.

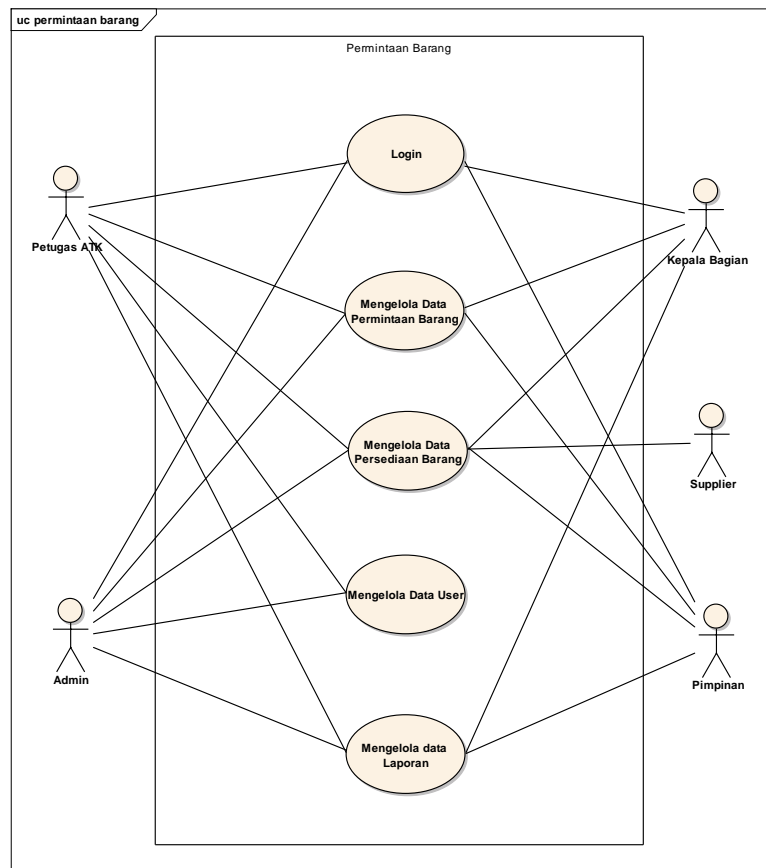

Gambar 2 Use Case Diagram

\section{c. Implementation And Unit Testing}

Berisi hasil implementasi sistem yang telah dirancang

1) Implementasi User Interface Login

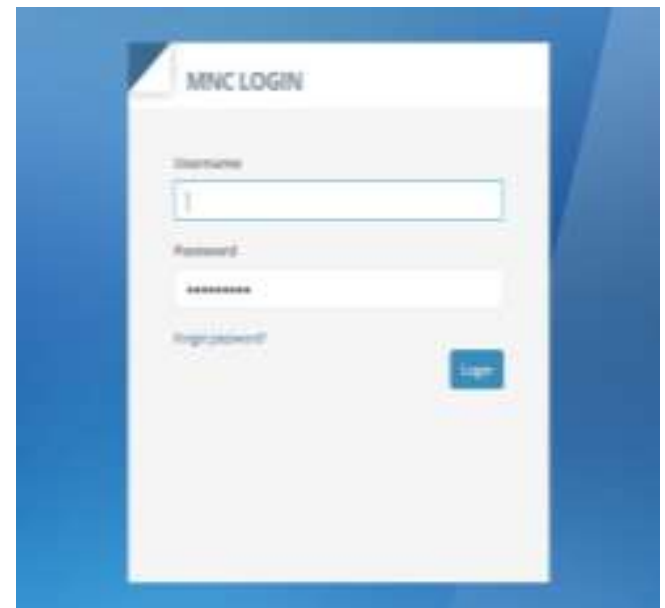

Gambar 2 Implementasi User Interface Login

\section{2) Implementasi User Interface Beranda Admin}

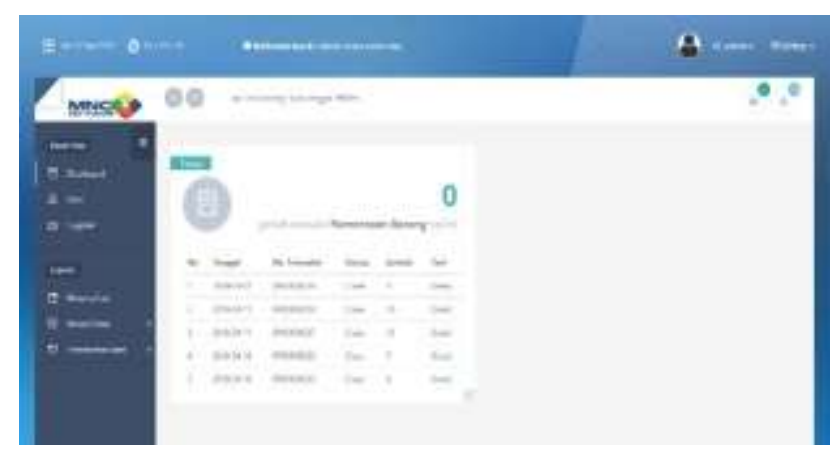

Gambar 3 Implementasi User Interface Beranda Admin

3) Implementasi User Interface kepala bagian

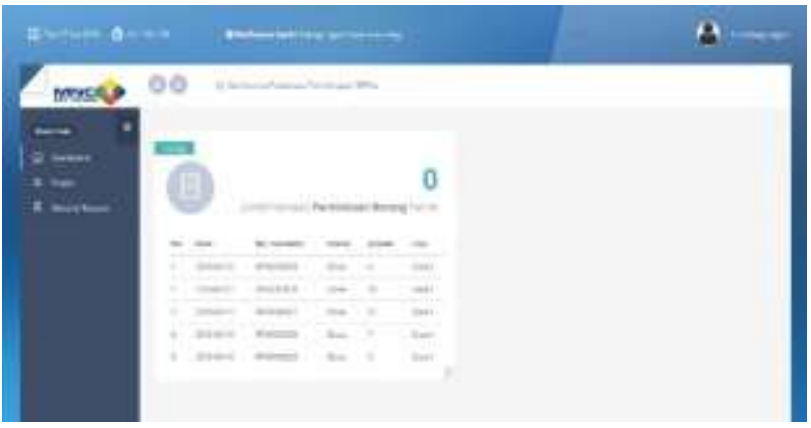

Gambar 4 Implementasi User Interface kepala bagian

4) Implementasi User Interface Tambah User

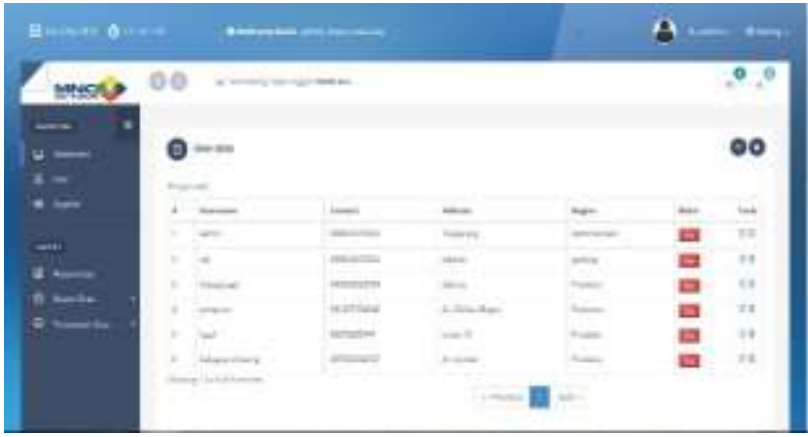

Gambar 5 Implementasi User Interface Tambah User

5) Implementasi User Interface ATK 


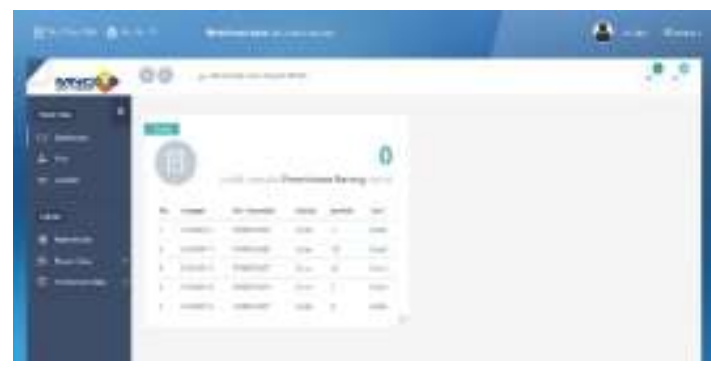

Gambar 6 Implementasi User Interface ATK

\section{d. Integration And System Testing}

Berisi hasil pengujian sistem yang sudah diimplementasi. Adapun metode pengujian yang dipakai adalah metode pengujian black box testing.

1) Pengujian Login

Tabel 1 Pengujian Login

\begin{tabular}{|l|l|l|l|}
\hline $\begin{array}{l}\text { Data yang } \\
\text { diinput }\end{array}$ & $\begin{array}{l}\text { Yang } \\
\text { diharapkan }\end{array}$ & Pengamatan & kesimpulan \\
\hline $\begin{array}{l}\text { Username } \\
\text { password }\end{array}$ & $\begin{array}{l}\text { Masuk ke } \\
\text { halaman } \\
\text { user }\end{array}$ & $\begin{array}{l}\text { Muncul } \\
\text { pesan } \\
\text { berhasil }\end{array}$ & $\begin{array}{l}\text { ( }) \text { diterima } \\
\text { () Ditolak }\end{array}$ \\
\hline
\end{tabular}

2) Pengujian kelola data administrator

Tabel 2 Pengujian kelola data administrator

\begin{tabular}{|l|l|l|l|}
\hline $\begin{array}{l}\text { Data yang } \\
\text { diinput }\end{array}$ & $\begin{array}{l}\text { Yang } \\
\text { diharapkan }\end{array}$ & Pengamatan & kesimpulan \\
\hline $\begin{array}{l}\text { Data } \\
\text { admin }\end{array}$ & $\begin{array}{l}\text { Memproses } \\
\text { data admin }\end{array}$ & $\begin{array}{l}\text { Muncul } \\
\text { pesan } \\
\text { berhasil }\end{array}$ & $\begin{array}{l}\text { ( }) \text { diterima } \\
\text { ( ) Ditolak }\end{array}$ \\
\hline
\end{tabular}

3) Pengujian Kelola Data User

Tabel 3 Pengujian Kelola Data User

\begin{tabular}{|l|l|l|l|}
\hline $\begin{array}{l}\text { Data yang } \\
\text { diinput }\end{array}$ & $\begin{array}{l}\text { Yang } \\
\text { diharapkan }\end{array}$ & Pengamatan & kesimpulan \\
\hline Data user & $\begin{array}{l}\text { Memproses } \\
\text { data user }\end{array}$ & $\begin{array}{l}\text { Muncul } \\
\text { pesan } \\
\text { berhasil }\end{array}$ & $\begin{array}{l}\text { ( }) \text { diterima } \\
\text { () Ditolak }\end{array}$ \\
\hline
\end{tabular}

4) Pengujian Kelola Data Pimpinan

Tabel 4 Pengujian Kelola Data Pimpinan

\begin{tabular}{|l|l|l|l|}
\hline $\begin{array}{l}\text { Data yang } \\
\text { diinput }\end{array}$ & $\begin{array}{l}\text { Yang } \\
\text { diharapkan }\end{array}$ & Pengamatan & kesimpulan \\
\hline $\begin{array}{l}\text { Data } \\
\text { pimpinan }\end{array}$ & $\begin{array}{l}\text { Memproses } \\
\text { data } \\
\text { pimpinan }\end{array}$ & $\begin{array}{l}\text { Muncul } \\
\text { pesan } \\
\text { berhasil }\end{array}$ & $\begin{array}{l}\text { ( }) \text { diterima } \\
\text { () Ditolak }\end{array}$ \\
\hline
\end{tabular}

5) Pengujian Kelola Data Permintaan Barang

Tabel 5 Pengujian Kelola Data Permintaan

\begin{tabular}{|l|l|l|l|}
\hline $\begin{array}{l}\text { Data yang } \\
\text { diinput }\end{array}$ & $\begin{array}{l}\text { Yang } \\
\text { diharapkan }\end{array}$ & Pengamatan & kesimpulan \\
\hline $\begin{array}{l}\text { Data } \\
\text { barang }\end{array}$ & $\begin{array}{l}\text { Memproses } \\
\text { data barang }\end{array}$ & $\begin{array}{l}\text { Muncul } \\
\text { pesan } \\
\text { berhasil }\end{array}$ & $\begin{array}{l}(\sqrt{ }) \text { diterima } \\
(\text { ) Ditolak }\end{array}$ \\
\hline
\end{tabular}

4. Kesimpulan

Berdasarkan hasil penelitian tentang Perancangan Sistem Informasi manajemen Permintaan Barang Berbasis Web Pada PT. MNC Sky Vision Tbk yang telah dilakukan penulis maka dapat diambil beberapa kesimpulan sebagai berikut:

a. Dengan adanya penggunaan sistem permintaan barang yang terkomputerisasi mengurangi banyaknya penggunaan kertas karena data tersimpan tidak lagi ditulis dalam bentuk kertas melainkan data yang tersimpan di dalam database.

b. Penggunaan aplikasi permintaan barang yang berbasiskan website maka pengolahan data data permintaan barang dapat dilalukan dengan cepat, karena permintaan yang di minta ka-bag masingmasing divisi dan penerimaan barang dapat di terima oleh sttaf ATK waktu yang sama berdasarkan waktu pembuatan permintaan barang.

c. Dengan menggunakan sistem komputerisasi dapat mengurangi dan meminimalisir kesalahan data dan laporan permintaan barang dan pengeluaran barang, karena permintaan yang masuk langsung di terima dan staff ATK memberikan konfirmasi perihal barang yang akan di keluarkan.

\section{Saran}

Dalam Perancangan sistem informasi manajemen permintaan barang berbasis web pada ini masih banyak terdapat kekurangan dan masih belum sempurna. Penulis berharap agar sistem ini dapat dikembangkan lagi untuk jadi lebih baik di masa yang akan datang. Berikut ini adalah saran untuk pengembangan lebih lanjut antara lain:

a. Agar lebih mengembangkan fitur dan fungsi yang lebih menarik pada Sistem informasi Manajemen Permintaan barang sehingga menghasilkan sistem yang lebih baik.

b. Penambahan fitur unduh untuk mencetak daftar permintaan barang-barang yang di lampirkan mempermudah kabag dalam melakukan 
pencetakan dokumen yang butuhkan ketika pimpinan meminta bukti laporan permintaan bulanan.

c. Aplikasi yang dibangun merupakan aplikasi berbasis web, sehingga internet merupakan bagian penting dari aplikasi berbasis web. Perlu diperhatikan bahwa aplikasi tidak hanya membutuhkan koneksi internet yang kuat, namun perlu diperhatikan hal terpenting adalah koneksi yang jarang putus sehingga dapat terhubung secara berkesinambungan. Koneksi yang selalu berjalan dengan lancar dapat meningkatkan daya guna dan fungsi dari sistem informasi tersebut.

\section{Daftar Pustaka}

JavaCreatifity. 2014. Panduan Cerdas Membangun Website Super Keren. Elek Media Komputindo. Jakarta.

Syahputra, A. 2003. Apache Web Server. Andi. Yogyakarta.

Peranginangin, K. 2006. Aplikasi WEB dengan PHP dan MySQL. Andi. Yogyakarta.

Raharjo, B. 2011. Membuat Database Menggunakan Mysql. Informatika. Bandung.

Gata, W. \& Gata, G. 2013. Sukses Membangun Aplikasi Penjualan dengan Java. Jakarta: Elex Media Komputindo.

Rosa, A.S, \& Shalahuddin. 2014 Rekayasa Perangkat Lunak Terstruktur dan Berorientasi Objek, Informatika Bandung.

Mustaqbal, M. S. M., Firdaus, R. F. F., \& Rahmadi, H. R. 2015, Pengujian Aplikasi Menggunakan Black Box Testing Boundary Value Analysis (Studi Kasus Aplikasi Prediksi Kelulusan SNMPTN). Jurnal Ilmiah Teknologi Terapan (JITTER); $1(3): 31-36$. 